\title{
Video Article \\ Isolation of CD133+ Liver Stem Cells for Clonal Expansion
}

\author{
C. Bart Rountree ${ }^{1}$, Wei Ding ${ }^{1}$, Hein Dang ${ }^{1}$, Colleen VanKirk ${ }^{2}$, Gay M. Crooks ${ }^{3}$ \\ ${ }^{1}$ Department of Pediatrics and Pharmacology, Pennsylvania State College of Medicine \\ ${ }^{2}$ Department of Pharmacology, Pennsylvania State College of Medicine \\ ${ }^{3}$ Department of Pediatrics, University of California Los Angeles, School of Medicine
}

Correspondence to: C. Bart Rountree at crountree@hmc.psu.edu

URL: https://www.jove.com/video/3183

DOI: doi: $10.3791 / 3183$

Keywords: Developmental Biology, Issue 56, CD133, liver stem cell, oval cell, liver cancer stem cell, stem cell, cell isolation, non-parenchymal fraction of liver, flow cytometry

Date Published: 10/10/2011

Citation: Rountree, C.B., Ding, W., Dang, H., VanKirk, C., Crooks, G.M. Isolation of CD133+ Liver Stem Cells for Clonal Expansion. J. Vis. Exp. (56), e3183, doi:10.3791/3183 (2011).

\section{Abstract}

Liver stem cell, or oval cells, proliferate during chronic liver injury, and are proposed to differentiate into both hepatocytes and cholangiocytes. In addition, liver stem cells are hypothesized to be the precursors for a subset of liver cancer, Hepatocellular carcinoma. One of the primary challenges to stem cell work in any solid organ like the liver is the isolation of a rare population of cells for detailed analysis. For example, the vast majority of cells in the liver are hepatocytes (parenchymal fraction), which are significantly larger than non-parenchymal cells. By enriching the specific cellular compartments of the liver (i.e. parenchymal and non-parenchymal fractions), and selecting for CD45 negative cells, we are able to enrich the starting population of stem cells by over 600 -fold. The proceduresdetailed in this report allow for a relatively rare population of cells from a solid organ to be sorted efficiently. This process can be utilized to isolateliver stem cells from normal murine liver as well as chronic liver injury models, which demonstrate increased liver stem cell proliferation. This method has clear advantages over standard immunohistochemistry of frozen or formalin fixed liver as functional studies using live cells can be performed after initial co-localization experiments. To accomplish the procedure outlined in this report, a working relationship with a research based flow-cytometry core is strongly encouraged as the details of FACS isolation are highly dependent on specialized instrumentation and a strong working knowledge of basic flowcytometry procedures. The specific goal of this process is to isolate a population of liver stem cells that can be clonally expanded in vitro.

\section{Video Link}

The video component of this article can be found at https://www.jove.com/video/3183/

\section{Protocol}

All solutions, media, instruments, filters, and tubes should be sterile and handled with sterile technique to reduce the risk of contamination.

Prepare all buffers and media 24 hours in advance and store at $4^{\circ} \mathrm{C}$.

\section{Parenchymal and non-parenchymal separation from whole liver}

1. Prepare the enzyme solution for digestion using a $15 \mathrm{cc}$ tube with screw top in $10 \mathrm{ml}$ sterile PBS containing $5 \mathrm{mg}$ collagenase, $5 \mathrm{mg}$ pronase, and $1 \mathrm{mg}$ DNAse.

2. Euthanize mouse using institution approved (Institutional Animal Care and Use Committee) method such as $\mathrm{CO}_{2}$ asphyxiation. Wipe abdominal area of euthanized animals with $70 \%$ ethanol solution. Using sterile instruments, open abdominal cavity and explant liver en-block. Remove gall-bladder from explanted liver. Transfer whole liver to laminar flow hood in closed sterile dish.

3. This procedure is completed in a laminar flow hood. Using a sterile razor blade, mince liver with combination of multiple horizontal and vertical cuts for 1 minute in sterile dish. Place $1 / 4$ of minced liver pulp in 15 cc tube with $10 \mathrm{cc}$ PBS with collagenase, pronase, and DNAse from step 1.1 above. Repeat with each $1 / 4$ minced liver.

4. Place tubes with $1 / 4$ minced liver pulp and enzymes into water bath at $37^{\circ} \mathrm{C}$ for 45 minutes, with shaker at $1-2$ cycles/second. Wipe tubes with $70 \%$ ethanol after removal from water bath prior to transfer to laminar flow hood.

5. This procedure is completed in a laminar flow hood. Strain digested liver pulp through 70 micron mesh filter to collect into a sterile dish. Using $2 \mathrm{ml}$ aliquots of sterile DMEM:F12 media with $10 \%$ heat inactivated fetal bovine serum, rinse the filter and use the rubber end of a syringe plunger to mash the digested pulp through the filter. Repeat 5 times to make total volume of filtrate approximately $20 \mathrm{~mL}$. Divide the filtrate into 2 equal $15 \mathrm{~mL}$ tubes.

6. All transfers should be completed in laminar flow hood, and use refrigerated centrifuge at $4^{\circ} \mathrm{C}$ if available. Centrifuge at $50 \times \mathrm{g}$ for $1 \mathrm{minute}$. Save supernatant \#1 and discard parenchymal pellet. Centrifuge supernatant \#1 at $50 \times \mathrm{g}$ for 1 minute. Save supernatant \#2 and discard pellet. Centrifuge supernatant \#2 at $50 \times \mathrm{g}$ for 1 minute. Save supernatant \#3 and discard pellet. Centrifuge final supernatant \#3 for $180 \times \mathrm{g}$ for 8 minute to obtain non-parenchymal fraction. 


\section{Red cell lysis}

Work in laminar flow hood, keep cells cold, and use solutions cooled to $4^{\circ} \mathrm{C}$.

1. The night before the procedure, prepare red cell lysis buffer by diluting 10X concentration stock BD Pharm Lyse buffer with a 1:10 dilution with sterile distilled water. $1 \mathrm{X}$ solutionshould be stored for 30 days at $4^{\circ} \mathrm{C}$.

2. The night before the procedure, prepare Miltenyi buffer using sterile PBS, $0.5 \%$ bovine serum Albumin, and $2 \mathrm{mM}$ EDTA. Filter solution using vacuum filter unit with 0.45 micron filter. Cover top of tilter unit with original plastic lid and secure with plastic wrap. Storeentire filter unit at $4^{\circ} \mathrm{C}$ for 12 hours to degas EDTA. Filter unit can be replaced with standard sterile cap after 12 hours.

3. This procedure is completed in a laminar flow hood. Using a $5 \mathrm{ml}$ sterile tube, re-suspend non-parenchymal pellet from step 1.6 above into 1 $\mathrm{mL}$ of $1 \mathrm{X}$ diluted red blood cell lysis buffer from 2.1 above. Cap the tube for transfer out of the laminar flow hood.

4. Gently vortex for 5 seconds and incubate for 15 minutes at $4^{\circ} \mathrm{C}$ protected from light.

5. Centrifuge at $200 \mathrm{xg}$ for 5 minutes.

6. This procedure is completed in a laminar flow hood. Discard lysed RBCs in supernatant, and re-suspend pellet in $1 \mathrm{ml}$ ice-cold and sterile Miltenyi buffer.

7. Centrifuge at $200 \times \mathrm{g}$ for 5 minutes.

8. This procedure is completed in a laminar flow hood. Discard supernatant and re-suspend pellet in $1 \mathrm{ml}$ ice-cold and sterile Miltenyi buffer.

9. Remove $10 \mu \mathrm{l}$ of PBS cell suspension and add $10 \mu$ tryan blue. Count remainingnon-parenchymal cells using hemocytometer.

\section{CD45 hematopoietic cell depletion from non-parenchymal fraction}

Work in laminar flow hood, keep cells cold, and use solutions cooled to $4^{\circ} \mathrm{C}$.

1. Suspend cells in $100 \mu \mathrm{L}$ of Miltenyi buffer per 107 cells up to 108 total cells.

2. Apply $20 \mu \mathrm{L}$ Miltenyi CD45 microbead antibody for each 107 cells and incubate at $4^{\circ} \mathrm{C}$ for 15 minutes.

3. Add additional $2 \mathrm{ml}$ Miltenyi buffer and centrifuge at $200 \times \mathrm{g}$ for 5 minutes. Remove supernatant. Re-suspend cell pellet (up to 108 total cells) in $1 \mathrm{ml}$ Miltenyi buffer.

4. In laminar flow hood, filter cells using Miltenyi LD magnetic column. Start by placing column in magnetic holder (Miltenyi MidiMACS or QuadroMACS). Place sterile $5 \mathrm{ml}$ tube below filter to catch filtrate. Prepare column by loading $2 \mathrm{ml}$ Miltenyi buffer.

5. Once pre-filter wash is complete, load cells onto LD column. Once the cell suspension is within the column, add $1 \mathrm{ml}$ Miltenyi buffer and repeat $1 \mathrm{ml}$ Miltenyi buffer wash 2 additional times. Do NOT use plunger provided with column to increase speed of filtration. ONLY collect filtrate when the filter in placed in the magnetic holder.

6. Centrifuge the collected filtrate of approximately $5 \mathrm{ml}$ (the column holds the remaining $1 \mathrm{ml}$ ) of CD45-depleted non-parenchymal cells at $200 \mathrm{x}$ $\mathrm{g}$ for 5 minutes. Discard the column with the retained CD45 positive cells.

\section{Flow cytometry isolation of CD133 positive cells}

1. Prepare oval cell media. Use $1: 1$ DMEM:F12 medium with $10 \%$ heat inactivated fetal calf serum as base, and add insulin $(1 \mu \mathrm{g} / \mathrm{ml}), \mathrm{HEPES}$ ( $5 \mathrm{~mol} / \mathrm{L})$, and Penicillin/Streptomycin (1\% volume/volume). Filter solution using vacuum filter unit with 0.45 micron filter.

2. Re-suspend cells in Miltenyi buffer at $100 \mu \mathrm{L}$ per $10^{7}$ cells. Add $2 \mu \mathrm{L}$ of CD133-PE conjugated antibody. Using a second group of cells, incubate with IgG-PE conjugated antibody as a control. Retain a third group of cells without staining as an unstained control for FACS.

3. Incubate at $4^{\circ} \mathrm{C}$ for 15 minutes in the dark. Re-suspend in $2 \mathrm{ml}$ staining buffer. Centrifuge at $200 \times \mathrm{g}$ for 5 minutes. Discard supernatant and re-suspend pellet in $1 \mathrm{ml}$ Miltenyi buffer.

4. This step is conducted using standard flow cytometry cell sorting procedures, which may be institution specific. Using unstained cells and lgG PE stained cells, adjust sorting parameters for optimized gating of CD133+ cell population. PE (R-Phytoerythrin) can generally be used with any flow cytometer that has a laser that emits at $488 \mathrm{~nm}$. The peak emission for PE is $575 \mathrm{~nm}$ and is detected in the FL-2 channel. Note: Using a BD FACS Calibur or BD FACS Vantage machines, with the Cell Quest program for data collection, we use Forward Scatter and Side Scatter view in the log scale to identify cell populations, with side scatter set to 250 . FL1 and FL2 are both in log scale and set to 550. These parameters provide an initial starting place to view liver non-parenchymal cells, and are adjusted as needed based on staining intensity of positive and negative populations.

5. Isolate the CD133+ cell population using CD133+ gate and collect the cells in sterile filtered cell media.

\section{Cell culture methods}

1. Centrifuge FACS collected cells at $200 \times \mathrm{g}$ for 5 minutes. Re-suspend cell pellet in oval cell media with approximately 5000 cells per ml. May start with higher concentrations, up to $50,000 \mathrm{cells} / \mathrm{ml}$ for initial experiments, and reduce as technique improves and overall cell viability and yield improves.

2. Plate cells onto BD Biocoat Laminin coated 96 well plates using $1000 \mathrm{cells} / \mathrm{cm}^{2}$. Place in humidified cell culture incubator at $37^{\circ} \mathrm{C}$, with $5 \%$ $\mathrm{CO}_{2}$. After 24 hours, add Hepatocyte Growth Factor $(50 \mathrm{ng} / \mathrm{nl})$ and Epidermal Growth Factor $(20 \mathrm{ng} / \mathrm{ml})$.

3. For single cells, isolate cells directly into $50 \mu \mathrm{l}$ of oval cell media in each well of a 96 well Laminin coated plate. Use single cell FACS settings for strict selection of one positive cell only. After 24 hours, add $50 \mu \mathrm{l}$ of oval cell media with HGF and EGF as above in step 5.2. Change media fully after 5-7 days.

4. Once the expanding colonies are greater than $50 \%$ confluent, which typically occurs after 2 weeks, depending on total number of cells plated and cell viability, the cells may be split $1: 3$ as below.

5. Split cells using Trypsin $0.05 \%$-EDTA. Apply just enough to cover well bottom, $50-100 \mu \mathrm{L} /$ well on 96 well plate. Place in incubator at $37^{\circ} \mathrm{C}$ for 3-5 minutes.

6. Add $100 \mu \mathrm{L}$ of media to each well and transfer all liquid to $5 \mathrm{ml}$ tube. Add $1 \mathrm{~mL}$ media to each tube and centrifuge at $200 \times \mathrm{g}$ for $5 \mathrm{minutes}$. 
7. Re-suspend cells in media plate in laminin coated dish, using cells from 1 well to plate into 3 new wells (1:3 ratio).

\section{Confirmation of bi-potential status using RT-PCR}

This procedure is detailed in the RNeasy protocol handbook, which is supplied with the RNeasy Kit.

1. Use RNeasy micro columns for 96 well plate colonies. Aspirate culture media from each well. Add $75 \mu$ l Buffer RLT (from RNeasy Kit) directly to each well. Scrape plate bottom with sterile rubber policeman. Pipettelysate into micro-centrifuge tube and vortex mixture for 1 minute. Add $70 \%$ ethanol to lysates and mix by pipetting.

2. Transfer the solution to RNeasy column placed in a $2 \mathrm{ml}$ collection tube (as supplied in RNeasy Kit) and centrifuge in micro-centrifuge for 15 seconds at 10,000 rpm. Discard eluted filtrate.

3. Re-use the collection tube. Add $350 \mu \mathrm{L}$ Buffer RW1 (RNeasy Kit) to the RNeasy column and centrifuge for 15 seconds at $10,000 \mathrm{rpm}$ to wash the column membrane. Discard eluted wash.

4. Add $10 \mu \mathrm{L}$ DNase I stock solution to $70 \mu \mathrm{L}$ Buffer RDD (both supplied in RNeasy Kit).Add the $80 \mu \mathrm{L}$ DNase I Buffer RDD incubation mix to the RNeasy column membrane and incubate for 15 minutes at room temperature.

5. Add $350 \mu \mathrm{L}$ Buffer RW1 (RNeasy kit) to the RNeasy column and centrifuge for 15 seconds at 10,000 rpm to wash the membrane. Discard eluted wash and collection tube.

6. Place the RNeasy column in a new $2 \mathrm{ml}$ collection tube (supplied in RNeasy kit). Add $500 \mu \mathrm{L}$ Buffer RPE(RNeasy Kit) to the RNeasy column and centrifuge for 15 seconds at 10,000 rpm to wash the membrane. Discard eluted wash.

7. Prepare $80 \%$ ethanol using RNase-free water (RNeasy Kit). Add $500 \mu \mathrm{L}$ of $80 \%$ ethanol to the RNeasy columnand centrifuge for 2 minutes at $10,000 \mathrm{rpm}$. Discard eluted wash.

8. Place the RNeasy column in a new $2 \mathrm{ml}$ collection tube (RNeasy Kit) and centrifuge at full speed for 5 minutes. Discard any eluted wash and collection tube.

9. Place the RNeasy column in a new $1.5 \mathrm{ml}$ collection tube (RNeasy kit). Add $14 \mu \mathrm{L}$ RNase-free water (RNeasy Kit) to the center of the column membrane and centrifuge for 1 minute at full speed. Collect filtrate with purified RNA and transfer to ice if creating cDNA immediately or store at minus $80^{\circ} \mathrm{C}$ for future use.

10. Reverse transcription using Omniscript.Dilute RNase inhibitor to a final concentration of 10 units/ $\mu \mathrm{L}$ in ice-cold $1 \times$ Buffer RT. Vortex for 5 seconds, and pulse centrifuge for 5 seconds. Prepare a fresh master mix on ice according to page 13 of Omniscript protocol. Vortex for 5 seconds, and pulse centrifuge for 5 seconds. Recommend to prepare a volume of mastermix $10 \%$ greater than that required for the total required for all reactions.

11. Add template RNA to the individual tubes containing master mix. Vortex for 5 seconds, and pulse centrifuge for 5 seconds. Incubate for 60 $\min$ at $37^{\circ} \mathrm{C}$.

12. PCR amplification of hepatocyte (Albumin) and cholangiocyte specific genes using HotStarTaq DNA polymerase. Prepare reaction mix per page 15 of HotStarTaq protocol book. Recommend diluting stock primers to concentration of $20 \mathrm{pm} / \mu \mathrm{l}$, and with $1 \mu \mathrm{L} / \mathrm{reaction}$ tube used for forward and reverse primers. Depending on number of cells initially used for RNA extraction, we recommend dividing final cDNA among 3 reaction tubes ( $\beta$-actin for loading control, Albumin, and KRT19) to start.

13. PCR primer design is listed in Table 1.

14. Place reaction tubes into thermocycler. Recommend following program for initial experiments: $95^{\circ} \mathrm{Cfor} 15$ minutes $\times 1 \mathrm{cycle}$ followed by $95^{\circ} \mathrm{C}$ for 30 seconds, $55^{\circ} \mathrm{C}$ for 30 seconds, $72^{\circ} \mathrm{C}$ for 30 seconds $\times 35$ cycles, followed by $72^{\circ} \mathrm{C}$ for 10 minutes.

15. PCR products are analyzed using ethidium bromide impregnated agarose gel.

\section{Confirmation of tumor potential of CD133+ stem cells}

1. This procedure can be done with freshly isolated cells from step 4 or using cells that have been cultured from step 5 . We recommend performing initial experiments with cultured cells, as freshly isolated cells will have reduced viability and reduced yield.

2. Trypsinize cells using Trypsin $0.05 \%$-EDTA from step 5.5 above. After $3-5$ minute incubation at $37^{\circ} \mathrm{C}$, add $100 \mu \mathrm{L}$ of media to each well and transfer all liquid from each well to individual $5 \mathrm{ml}$ tubes ( 1 well = 1 tube). Add $1 \mathrm{ml}$ media to each tube and centrifuge at $200 \times \mathrm{g}$ for 5 minutes.

3. Re-suspend cells in $1 \mathrm{ml}$ ice cold PBS. Remove $10 \mu$ of PBS cell suspension and add $10 \mu$ trypan blue. Using trypan blue exclusion, determine numbers of live cells. If using FACS isolated cells, cell number will be determined by FACS isolation count.

4. Centrifuge cells at $200 \times \mathrm{g}$ for 5 minutes and re-suspended in PBS at a concentration of $1 \times 10^{6}$ live cells/100 $\mu \mathrm{l}$. Add $100 \mu \mathrm{l} \mathrm{Matrigel}$. Sixweek-old immune-deficient Nude mice were injected subcutaneously using 28 gague needle. Inject $1 \times 10^{6}$ cells in $200 \mu \mathrm{l}$ per site.

5. Mice are monitored for tumor growth daily. Once tumors form, typically after 3-4 weeks incubation, tumor volume is measured using calipers (height $\mathrm{x}$ length $\mathrm{x}$ width).

\section{Representative Results:}

From normal, healthy murine liver, the expected cellular yield of CD133+liver stem cells is 1,000 to 5,000 per liver. These cells are relatively rare in quiescent liver and will not expand well in culture. We do not recommend using single cell analysis on normal liver and the yield of viable cells that will expand is extremely low.

For livers with significant chronic injury, such as the DDC $0.1 \%$ diet for 6 weeks ${ }^{1}$ or genetic modification resulting in chronic injury, such as the MAT1 $^{-/-}$or liver specific Pten ${ }^{-/}$mice, ${ }^{2-4}$ the expected number of cells isolated increases, with up to 100,000 cells isolated/liver (Figure 2). If using genetic models, knowledge of spontaneous tumor rate is critical, as these procedures for liver stem cell isolation should be conducted in tumor free animals. For example, if the MAT1 $1 a^{-/-}$model forms spontaneous tumors at 18 months, we recommend using animals no later than $15-16$ months, prior to any reported spontaneous tumors. 
Isolation of single cells from chronic injury models will yield several (3-9 colonies/96 well plate) colonies that expand from single cells once the procedure is mastered, and cell viability is ensured. Figure 3 present representative phase contrast images of colonies derived from single CD133+ cells expanded after 7 days.

Confirmation of bi-potential status is conducted using Albumin and Krt19 RT-PCR. Colonies from expanded single cells will demonstrate both expression for markers of hepatocytes (Albumin) and cholangiocytes (Krt19). Figure 4 demonstrates bi-potential expression from three isolated colonies, with approximately 25 cells/colony at 7 days.

CD133+ stem cells from normal liver and chemically induced liver injury (e.g. DDC $0.1 \%$ diet for 6 weeks) will not form tumors in nude mice CD133+ stem cells from specific genetic models (MAT1 $\mathrm{a}^{-/-}$or liver specific Pten $^{-/-}$mice) will form tumors in nude mice if isolated late in late pre-tumor chronic injury phase. This tumor forming phenotype is currently identified as a cancer stem cell. ${ }^{2-4}$ For example, the MAT1 $1 a^{-/-}$mice form spontaneous liver tumors at 18 weeks of age. CD133+ liver stem cells isolated at 15-16 weeks, during a late chronic injury phase of liver disease, will form tumors in nude mice. Figure 5 demonstrates representative tumors from bilateral injection of $1 \times 10^{6}$ cells expanded in vitro from single CD133+ liver stem cells.

\begin{tabular}{|c|c|c|}
\hline Gene & Forward Primer & Reverse Primer \\
\hline$\beta$-Actin & 5'-TGTTACCAACTGGGACGACA-3' & 5'-GGGGTGTTGAAGGTCTCAAA-3' \\
\hline Albumin & 5'-CATGCCAAATTAGTGCAGGA-3' & 5'-GCTGGGGTTGTCATCTTTGT-3' \\
\hline Keratin 19 & 5'-TGCTGGATGAGCTGACTCTG-3' & 5'-AАTCCACСТCСАСАСТGACC-3' \\
\hline
\end{tabular}

Table 1: Primer design for RT-PCR

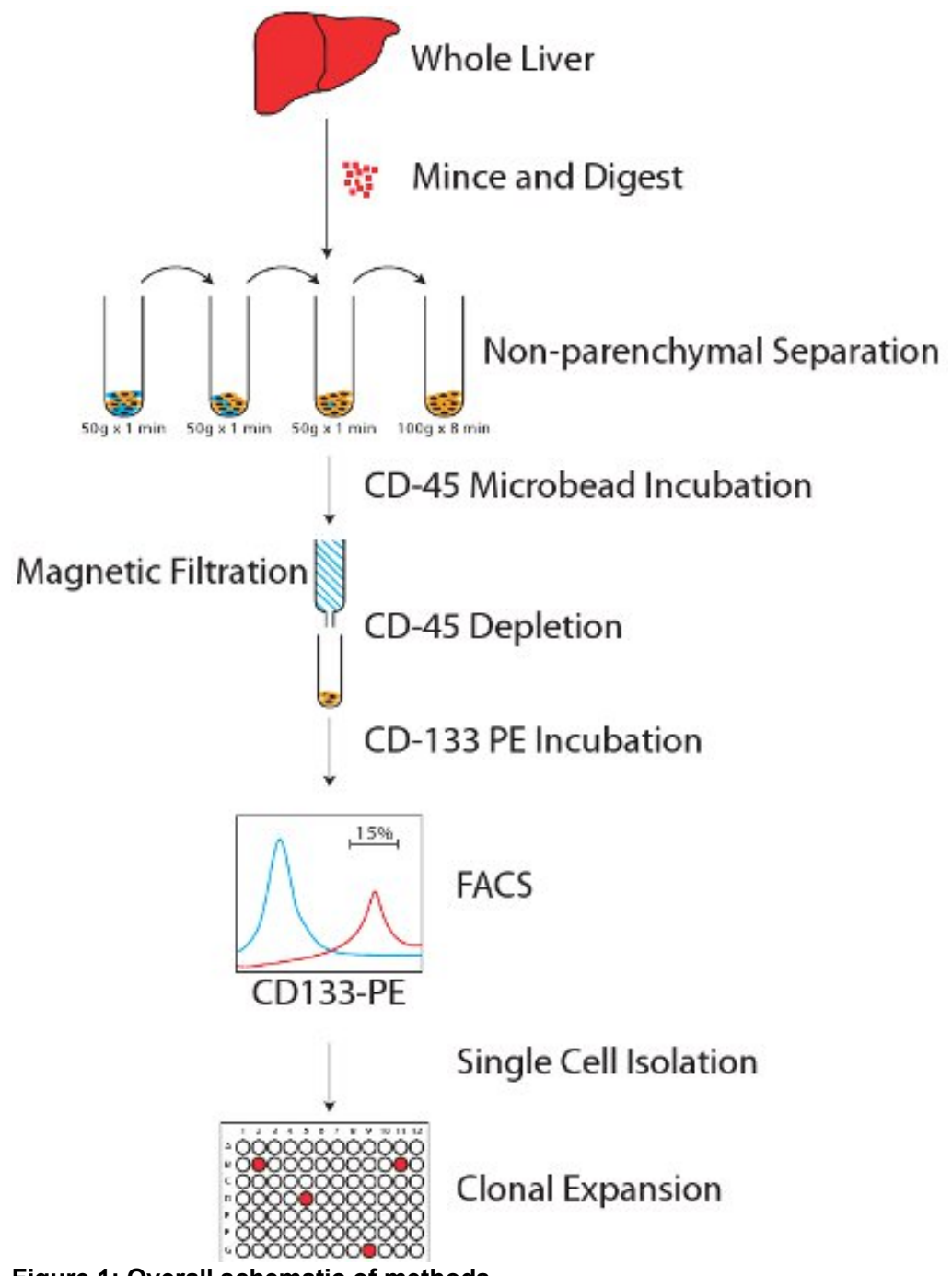

Figure 1: Overall schematic of methods. 

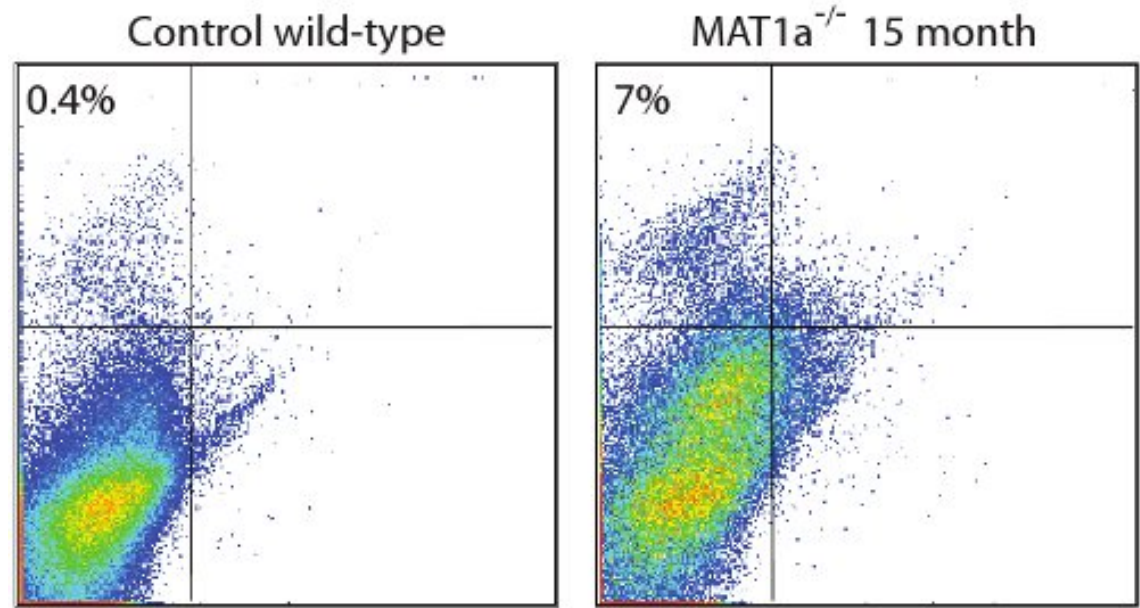

FL-1

Figure 2: CD133+ liver stem cells identified in highly enriched CD45 depleted non-parenchymal fraction. Control uninjured liver from wild-type mice demonstrates $0.4 \%$ CD133+ cells within the highly enriched CD45 depleted non-parenchymal fraction. In the genetic knock-out MAT1 $^{--/}$, which is a model of chronic liver injury, the CD133 population expands 10 fold or more in the same highly enriched fraction.
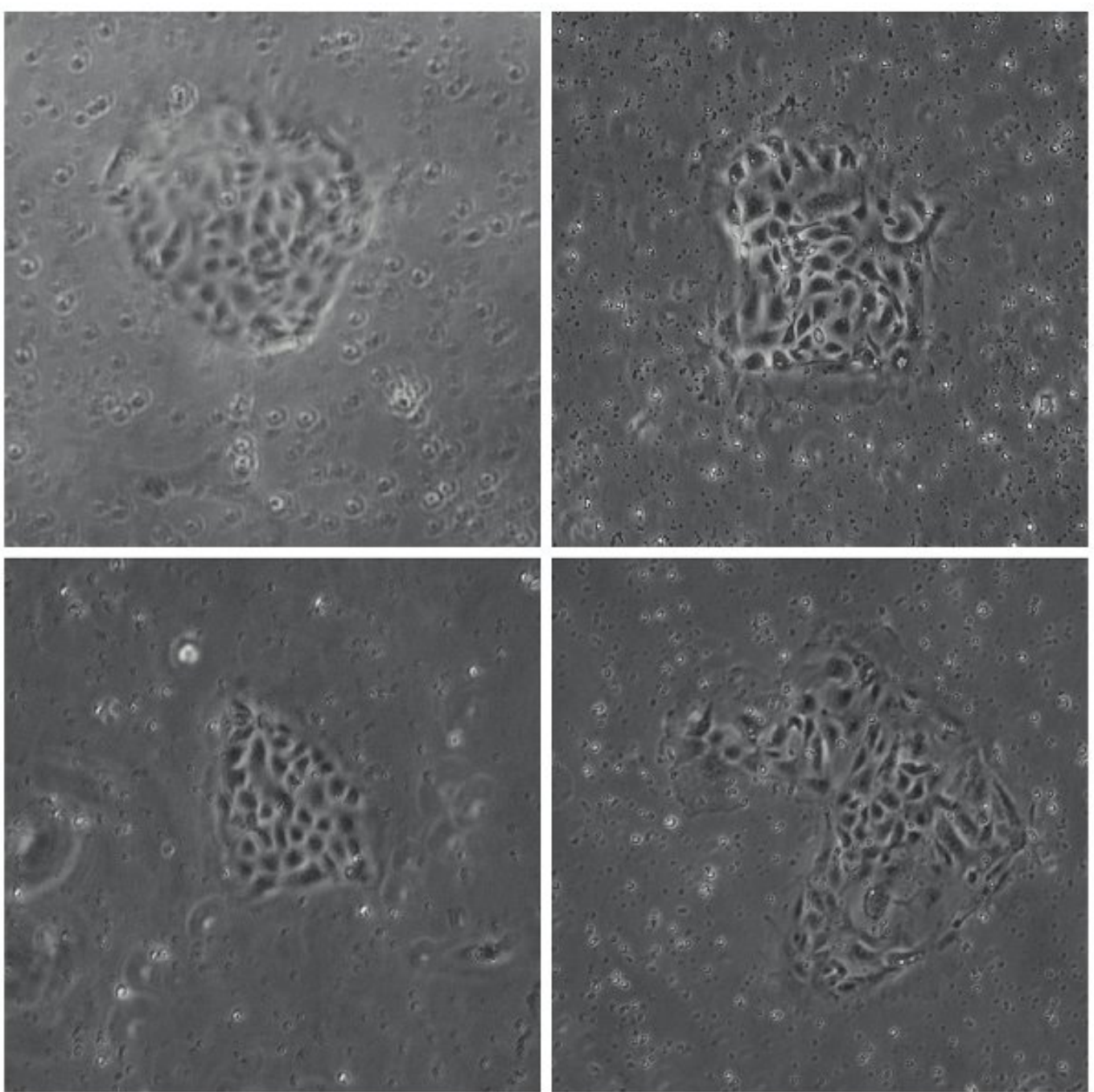

Figure 3: Expanding colonies from single CD133+ clones. Phase-contrast images of four colonies derived from single CD133+ cells expanded on laminin coated 96 well plates. 

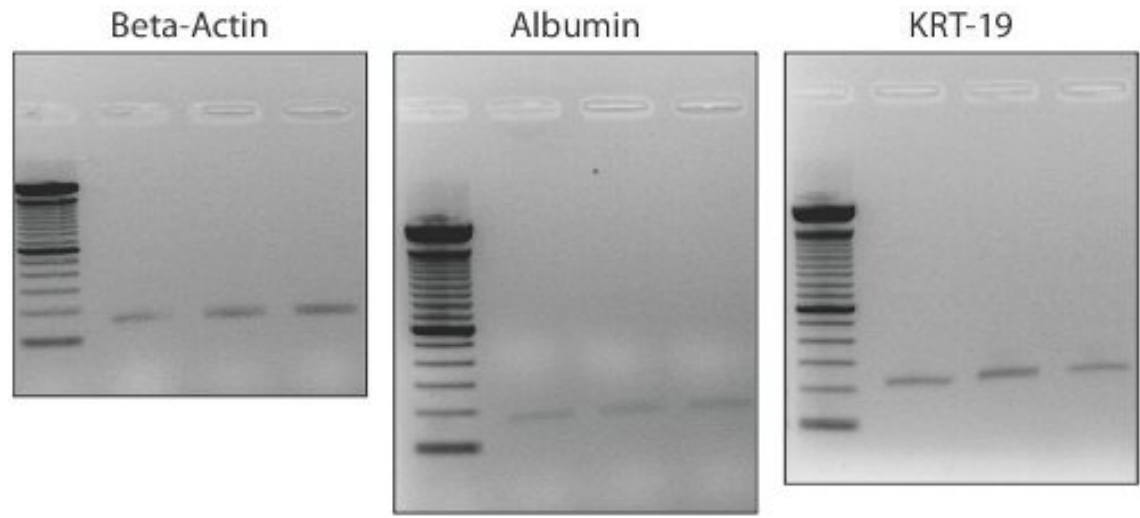

Figure 4: Bi-potential gene expression from CD133+ liver stem cell clonally expanded colonies. At Day 7 , colonies are approximately 25 cells. Gene expression demonstrates expression of hepatocyte marker Albumin and cholangiocyte marker Krt19, confirming bi-potential status of CD133+ cells.

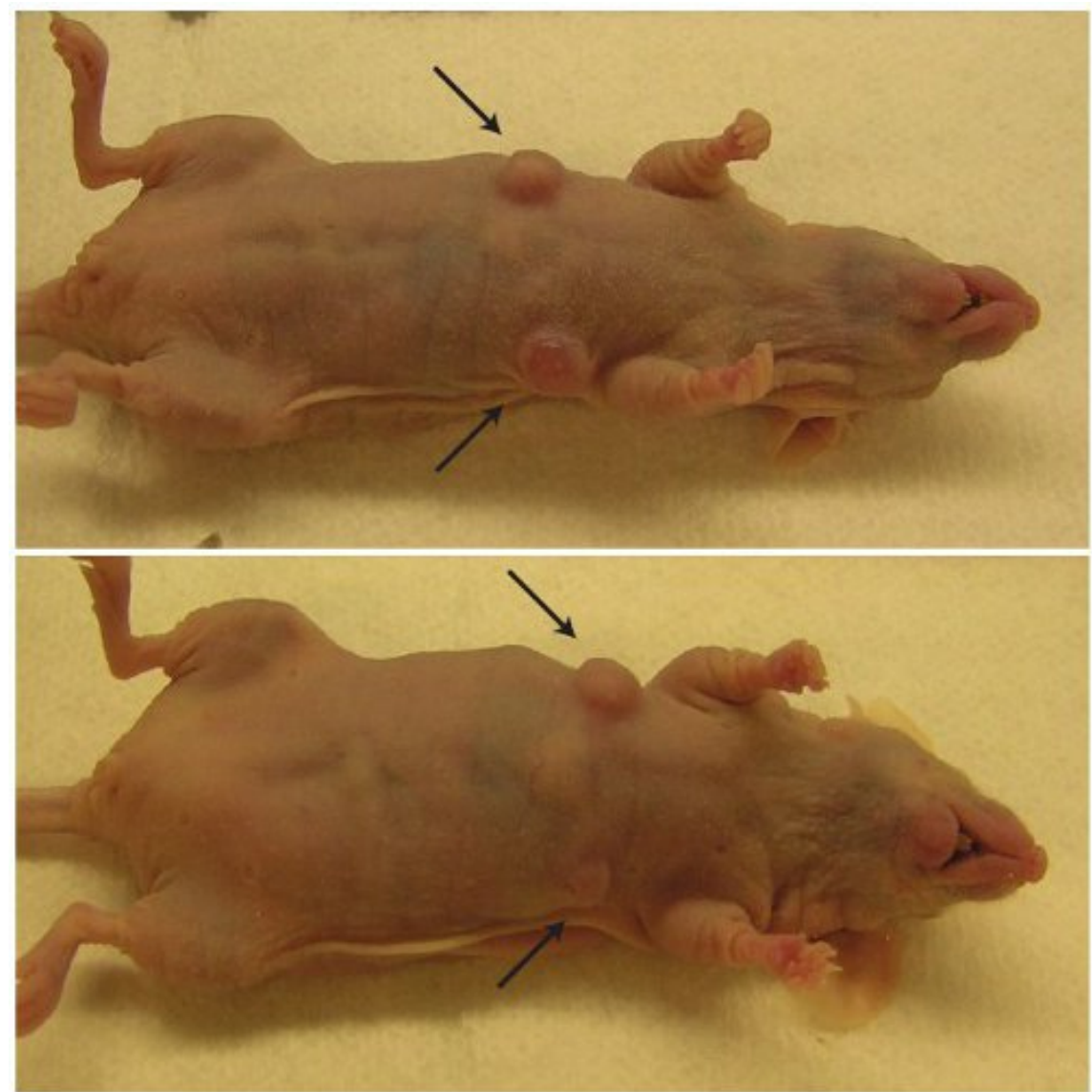

Figure 5: CD133+ liver stem cells form tumors in nude mice.Arrows indicate tumors growing 4 weeks after $1 \times 10^{6} \mathrm{CD} 133+$ cells injected from MAT1 $\mathrm{a}^{-/-}$model. CD133+ cells from toxin induced chronic liver injury, such as $\mathrm{CCl}_{4}$ or $0.1 \%$ DDC diet, do not form tumors. Tumor formation is used to identify malignant potential, or cancer stem cell phenotype within the stem cell population.

\section{Discussion}

Unlike the hematopoietic system, in which hematopoietic stem cells are responsible for maintaining a cellular differentiation system that replacesnormal physiologic turn-over of leukocytes, red blood cells, and platelets, liver stem cell, or adult liver progenitor cells, do not participate in normal liver homeostasis. ${ }^{5,6}$ After acute liver injury or partial hepatectomy, hepatocytes, as differentiated liver epithelium, undergo several rounds of proliferation to replace the lost liver mass. ${ }^{5,6}$ Only during chronic injury are liver stem cells observed to proliferate. ${ }^{1,5-11}$ These adult, organ specific stem cells are proposed to differentiate into both hepatocytes and cholangiocytes. ${ }^{1,5-8}$ Interestingly, the vast majority of liver cancer develops on the background of chronic injury, and thus liver stem cells are also hypothesized to be the precursors for a subset of liver cancer. $^{2-4,12-17}$ 
One of the major challenges to stem cell work in the liver is isolation of rare populations of cells for functional analysis. For example, the vast majority of cells in the liver are hepatocytes, which are significantly larger than cholangiocytes and other smaller non-parenchymal cells. By breaking the whole liver into cell compartments (large hepatocytes - parenchymal fraction and smaller cells - non-parenchymal fraction), and further selecting for CD45 negative cells (non-hematopoietic cells), we are able to enrich the starting population of stem cells by over 600fold. ${ }^{1,18-21}$ Of note, we are by no means indicating that the CD133+ population is a $100 \%$ pure stem cell population, but clearly represents a heterogeneous population of cells, with different lineage and repopulation potential. One of the major limitations of the field is definitions of stem cells and progenitor cells. We use the term "stem cell" more broadly in this work, but in strict definition, CD133+ non-parenchymal cells represent a bi-lineage progenitor population. Given the state of current stem and progenitor research in the liver, this report does provide a starting place for investigators who are interested in this field. As new markers emerge, such as EpCAM, ${ }^{22,23}$ or transcription factors, such as Sox9, ${ }^{24}$ they can be incorporated. For example, we have found a fairly high rate of overlap between EpCAM+ cells and CD133+ cells.

In this report, we detail a process for stem cell isolation from normal murine liver as well as chronic liver injury models, which demonstrate increased liver stem cell proliferation. This method has clear advantages over standard immunohistochemistry of frozen or formalin fixed liver as functional studies using live cells can be performed after isolation. ${ }^{1,3,4}$ The specific goal of this process is to isolate a relatively pure population of liver stem cells that can be clonally expanded in vitro.

The primary limitation to this procedure is that the majority of cells isolated will not be viable after flow cytometry (see Trouble Shooting section). This is the result of the hours required to prepare the cells, and the numerous procedures required to refine the population prior to isolation. If the liver is digested in single cell suspension for immediate FACS analysis, the size difference between hepatocytes and other non-parenchymal cells will make effective FACS gate creation impossible. If the liver non-parenchymal cells are utilized, without elimination of hematopoietic cells, there is a risk that a significant number of CD133+ cells may be of hematopoietic origin may contaminate the fraction. Furthermore, by processing the cells through the Miltenyi filter, only single cells and very small clusters of cells are collected. This ensures that the sample will not clog the FACS intake needle.

Alternatives for this procedure include modification for any alternative cell surface marker, such as CD49f, EpCAM, or combination of markers, such as CD133+EpCAM+A second published report utilizes a density gradient to isolate liver stem cells from a non-parenchymal fraction. This procedure requires an Ultra-centrifuge $(8000 \mathrm{x} \mathrm{g})$, adds significant time to the procedure, and in our experience, significantly reduced pre-FACS cellular yield and post-FACS viability.

Future experiments include a broader range of gene expression analysis, including fetal liver genes, such as HNF3, HNF4a, and afp.In addition, Western blot analysis and immunocytochemistry of expressed proteins can be utilized to confirm RT-PCR results of cells in culture.

One issue to note is recent work that identified CD133 expression on hepatic stellate cells. ${ }^{25}$ We now routinely screen our samples for markers of stellate cells (see Trouble Shooting section), and have not identified significant contamination in our fractions. This may be related to different techniques of liver digestion and cell isolation., ${ }^{2,3,26}$

Based on the fact that the majority of cells will not be viable immediately after FACS isolation, we recommend that the cells be plated, either as bulk CD133+ cells or single cells, prior to use in animals. 5-7 days in vitro will significantly improve results of tumor analysis. In addition, given the rigors of single cell isolation, this should only be conducted once colonies can be expanded from bulk CD133+ isolated cells. A more thorough discussion of the various culture conditions and scaffold proteins which may be utilized to culture liver stem and progenitor cells has been well characterized by Lola Reid. This work provides alternative conditions and modifications, which investigators may incorporate into their research program once basic isolation techniques are mastered. ${ }^{27,28}$ Dr. Reid's work also provides a more detailed analysis of the lineage biology and maturation between hepatic stem cells and committed progenitors.

In terms of in vivo tumor analysis, we have had success using freshly isolated cells and cells from clonally expanded CD133+ cells in vitro, primarily using $1 \times 10^{6}$ cells. We have focused ontwo genetic strains of chronic liver injury, the MAT1 $1 a^{-/-}$and liver specific Pten ${ }^{-1-}$ mice, and we have utilized both nude mice and wild-type mice as hosts for tumor growth. In our experience, CD133+ liver stem cells will only form tumors if they are isolated from significant liver injury models that are pre-malignant. Note that the tumors formed from CD133+ cells general have both hepatocellular carcinoma and cholangiocarcinoma features, suggesting a stem cell or progenitor cell origin to the tumors. ${ }^{2-4,29}$

Follow-up work after tumors are documented includes standard pathologic analysis of tumor tissue (H\&E staining) and immunohistochemical staining. In addition, tumors can be minced and digested for FACS analysis or re-culture. ${ }^{2-4,30}$

In conclusion, we have detailed a procedure for the isolation, expansion, and basic characterization of CD133+ liver stem cells and CD133+ cancer stem cells.

\section{Trouble Shooting:}

\section{CD45 contamination:}

For Step 3, if there is contamination of CD45+ cells, which can be assessed by adding a CD45-FITC Ab prior to FACS analysis and isolation, check to ensure that the CD45 microbead antibody is not expired and that the filtrate was collected only while the filter was in the magnetic holder. Any filtrate collected while the filter is not in the magnetic holder will contain CD45+ cells.

\section{Low cell number:}

For the uninjured liver, the total number of CD133+ non-parenchymal isolated may be less than 10,000 . These cells are rare in the quiescent liver. For a chronic injury model, such as the DDC $0.1 \%$ diet, the number will increase greatly to 100,000 cells. If the total cell number is significantly below these numbers, one issue to consider is the FACS Ab staining. Check to ensure that the CD133 Ab is not expired, as poor staining will result in a poor yield. Also, we recommend performing a FACS analysis of liver non-parenchymal cells to determine the relative population prior to attempting FACS isolation. 


\section{Low cell viability after FACS:}

One of the issues of viability may be related to how the cells are processed and over what time. Ideally, the entire cell isolation procedure, steps $1-4$, should be conducted without any delays between steps and completed in the same day. Any significant delay between steps $1-4$ will greatly reduce the cell viability. A second issue related to cell viability may be related to the sheath pressure used for FACS isolation. We recommend using a lower sheath pressure. Lastly, once the cells are isolated, they should be immediately plated, as any significant storage on ice after sorting will also reduce viability.

\section{CD133+ non-parenchymal heterogeneity:}

Recent reports indicate that hepatic stellate cells may also have CD133 expression and have some plasticity. ${ }^{25}$ Therefore, in addition to verifying bi-potency genes with Albumin and Krt19, additional verification can include genes associated with stellate cells, such as glial fibrillary acidic protein in quiescent stellate cells and alpha-smooth muscle actin and desmin in activated stellate cells. ${ }^{3,4,26}$ In addition, the CD133+ population represents a broader progenitor population. The addition of a second marker, such as EpCAM, may help to refine the population further, and limit heterogeneity.

\section{Disclosures}

Dr. Rountree receives research support from Bayer Pharmaceutics. Drs. Ding and Crooks and Ms. Dang and Ms. VanKirk have no disclosures to report.

\section{Acknowledgements}

Dr. Rountree acknowledges current support from the Children's Miracle Network, National Institute of Health, K08DK080928 and R03DK088013, and the American Cancer Society Research Scholar Award, MGO-11651. Dr. Rountree acknowledges that this procedure was initially developed and refined while funded by the Pediatric Scientist Development Program (NICHD Grant Award K12-HD00850).

\section{References}

1. Rountree, C.B., et al. A CD133-expressing murine liver oval cell population with bilineage potential. Stem Cells. 25, 2419-2429, (2007).

2. Ding, W., et al. CD133+ liver cancer stem cells from methionine adenosyl transferase 1A-deficient mice demonstrate resistance to transforming growth factor (TGF)-beta-induced apoptosis. Hepatology. 49, 1277-1286, (2009).

3. Rountree, C.B., Ding, W., He, L., \& Stiles, B. Expansion of CD133-expressing liver cancer stem cells in liver-specific phosphatase and tensin homolog deleted on chromosome 10-deleted mice. Stem Cells. 27, 290-299, (2009).

4. Rountree, C.B., Senadheera, S., Mato, J.M., Crooks, G.M., \& Lu, S.C. Expansion of liver cancer stem cells during aging in methionine adenosyltransferase 1A-deficient mice. Hepatology. 47, 1288-1297, (2008).

5. Michalopoulos, G.K. Liver regeneration. J. Cell. Physiol. 213, 286-300, (2007).

6. Fausto, N., Campbell, J.S. \& Riehle, K.J. Liver regeneration. Hepatology 43, S45-53, (2006).

7. Theise, N.D. Gastrointestinal Stem Cells. III. Emergent themes of liver stem cell biology: niche, quiescence, self-renewal, and plasticity. Am. J. Physiol. Gastrointest. Liver Physiol. 290, G189-193, (2006).

8. Wang, X., et al. The origin and liver repopulating capacity of murine oval cells. Proc Natl Acad Sci U. S. A. 100 Suppl. 1, 11881-11888, (2003).

9. Greenbaum, L.E. \& Wells, R.G. The role of stem cells in liver repair and fibrosis. Int. J. Biochem. Cell Biol. 43, 222-229, (2011).

10. Choi, S.S., Omenetti, A., Syn, W.K. \& Diehl, A.M. The role of Hedgehog signaling in fibrogenic liver repair. Int. J. Biochem. Cell. Biol. 43, 238-244, (2011).

11. Khurana, S., et al. Scopolamine treatment and muscarinic receptor subtype-3 gene ablation augment azoxymethane-induced murine liver injury. J. Pharmacol. Exp. Ther. 333, 639-649, (2010).

12. Sell, S. \& Leffert, H.L. Liver cancer stem cells. J. Clin. Oncol. 26, 2800-2805, (2008).

13. Lee, J.S., et al. A novel prognostic subtype of human hepatocellular carcinoma derived from hepatic progenitor cells. Nat. Med. 12, $410-416$, (2006).

14. Sell, S. \& Dunsford, H.A. Evidence for the stem cell origin of hepatocellular carcinoma and cholangiocarcinoma. Am. J. Pathol. 134, 1347-1363, (1989).

15. Amin, R. \& Mishra, L. Liver stem cells and tgf-Beta in hepatic carcinogenesis. Gastrointest Cancer Res. 2, S27-30, (2008).

16. Tang, Y., et al. Progenitor/stem cells give rise to liver cancer due to aberrant TGF-beta and IL-6 signaling. Proc Natl Acad Sci U. S. A. 105, 2445-2450, (2008).

17. Kitisin, K., Pishvaian, M.J., Johnson, L.B., \& Mishra, L. Liver stem cells and molecular signaling pathways in hepatocellular carcinoma. Gastrointest Cancer Res. 1, S13-21, (2007).

18. Rountree, C.B., et al. Bone marrow fails to differentiate into liver epithelium during murine development and regeneration. Hepatology. 45 , 1250-1260, (2007).

19. Shimano, K., et al. Hepatic oval cells have the side population phenotype defined by expression of ATP-binding cassette transporter ABCG2/ BCRP1. Am J Pathol. 163, 3-9, (2003).

20. Suzuki, A., et al. Flow cytometric isolation and clonal identification of self-renewing bipotent hepatic progenitor cells in adult mouse liver. Hepatology., (2008).

21. Suzuki, A., et al. Clonal identification and characterization of self-renewing pluripotent stem cells in the developing liver. J Cell Biol. 156, 173-184, (2002).

22. Yamashita, T., et al. EpCAM-positive hepatocellular carcinoma cells are tumor-initiating cells with stem/progenitor cell features. Gastroenterology. 136, 1012-1024, (2009). 
23. Yamashita, T., Budhu, A., Forgues, M., \& Wang, X.W. Activation of hepatic stem cell marker EpCAM by Wnt-beta-catenin signaling in hepatocellular carcinoma. Cancer Res. 67, 10831-10839, (2007).

24. Furuyama, K., et al. Continuous cell supply from a Sox9-expressing progenitor zone in adult liver, exocrine pancreas and intestine. Nat Genet. 43, 34-41, (2011).

25. Kordes, C., et al. CD133+ hepatic stellate cells are progenitor cells. Biochem Biophys Res Commun. 352, 410-417, (2007).

26. Berg, T., et al. Fibroblast Growth Factor 10 is critical for liver growth during embryogenesis and controls of hepatoblast survival via b-catenin activation. Hepatology., (2007)

27. Turner, R., et al. Human hepatic stem cell and maturational liver lineage biology. Hepatology 53, 1035-1045, (2011).

28. Wang, Y., et al. Lineage restriction of human hepatic stem cells to mature fates is made efficient by tissue-specific biomatrix scaffolds. Hepatology. 53, 293-305, (2011).

29. Galicia, V.A., et al. Expansion of hepatic tumor progenitor cells in Pten-null mice requires liver injury and is reversed by loss of AKT2. Gastroenterology. 139, 2170-2182, (2010).

30. Ding, W., et al. Epithelial-to-mesenchymal transition of murine liver tumor cells promotes invasion. Hepatology. 52, 945-953, (2010). 